\title{
JOURNAL.RU
}

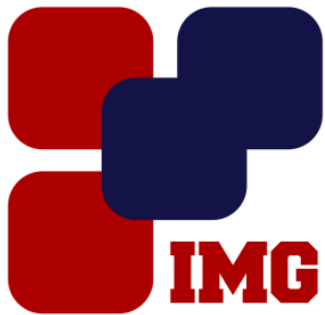

IVANOY

Management

Group

Овчинников Е.Л., Яшин С.С., Тарасенко Д.С., Давыдкин-Гогель М.М.

Самарский государственный медицинский университет

Самара, Россия

doi: $10.18411 / \mathrm{spc}-31-07-2017-02$

idsp 000001:spc-31-07-2017-02

\section{Тождественность законов Вебера - Фехнера и Стивенса}

\section{Аннотация}

Цель: Установление тождественности теоретического закона ВебераФехнера, устанавливающего относительные значения между интенсивностями звуков, и экспериментальным соотношением С.С. Стивенса, устанавливающим значение громкости через абсолютные параметры звука.

Результаты: В статье представлены законы Вебера- Фехнера и Стивенса, устанавливающие связь между интенсивностью (давлением) звуков и громкостью, которую они производят при их ощущении. Аналитические преобразования приводят к тождественности этих законов.

Ключевые слова: Закон Вебера - Фехнера, закон Стивенса, громкость звука.

\section{Abstract}

Purpose: Establishment of the identity of the theoretical Weber - Fechner law, which establishes the relative values between the intensities of sounds, and the experimental relation SS Stevens, setting the loudness value through absolute sound parameters.

Result: The article presents the laws of Weber - Fechner and Stevens, establishing a connection between the intensity (pressure) of sounds and loudness, they produce when they are sensed. Analytical transformations lead to the identity of these laws.

Keywords: The Weber - Fechner law, the Stevens law, the volume of sound. 


\section{Введение}

Теория слуха по H. Helmholtz [1], классические эксперименты по слуховым явлениям [2, 3], их теоретическое обоснование с выдвижением экспериментально-статистических положений $[4,5]$ и последующим анализом стали основой акустоволновой модели и теории слуха [6, 7] она получила солидное научное обоснование, представленная как полумодель в патенте [8], статьях $[9,10]$, и как полная модель и теория - в работе [11] и монографии [12]. Более того, она не только соответствует наблюдаемым результатам, но и позволяет прогнозировать многие слуховые эффекты [13-16]. На основе волновых процессов во внутреннем ухе, на которых построена морфофункциональная акустоволновая теория слуха [1], адекватно отражающая результаты классических экспериментов; разработана биофизическая модель восприятия человеком частоты, интенсивности и спектра звука, психофизическими коррелятами которых являются высота, громкость и тембр тонов.

Экспериментально установленный (Е.H. Weber, 1834) и математически обоснованный (G.Th. Fechner, 1858) закон Вебера - Фехнера утверждает, что существуют закономерная связь между силой воздействия внешних раздражителей и вызываемой ею субъективной реакцией рецепторной системы.

В психофизике слуха закон Вебера - Фехнера (Ю.А.Владимиров, 1983; В.О. Самойлов /ред., 1986; Я.А. Альтман /ред., 2003) регламентирует соотношение силы раздражителя, - относительной интенсивности звука I (звукового давления $\Delta \mathrm{p}$ ) относительно пороговой интенсивности Іо (порогового звукового давления $\Delta \mathrm{po}),-$ и её субъективного ощущения - громкости тона Е.

Таким образом, громкость тона является психоакустическим коррелятом восприятия слухом звуковой энергии (интенсивности звука, звукового давления). В настоящее время закон Вебера - Фехнера представляется для стандартной частоты

$$
\mathrm{f}_{\mathrm{c}}=1 \text { кГц в виде } \mathrm{E}=10 \lg \frac{\mathrm{I}}{\mathrm{I}_{\mathrm{o}}}=20 \lg \frac{\Delta \mathrm{p}}{\Delta \mathrm{p}_{\mathrm{o}}}, \text { фон. }
$$

Закон Вебера - Фехнера для стандартной частоты fc $=1$ кГц в форме (1) устанавливает единицу громкости слухового ощущения.

На этой частоте 1 дБ по шкале интенсивности принято считать равным 1 
дБ по шкале громкости: при этом 1 дБ громкости характеризует уровень слухового ощущения и называется фоном.

Громкость звука Е произвольной интенсивности I (звукового давления $\Delta \mathrm{p})$, в фонах и декафонах (1 дафон $=10$ фон), на стандартной частоте определяется как

$$
\mathrm{E}=10 \lg \frac{\mathrm{I}}{\mathrm{I}_{\mathrm{o}}}, \text { фон }=\lg \frac{\mathrm{I}}{\mathrm{I}_{\mathrm{o}}}, \text { декафон. }
$$

С учётом связи интенсивности звука со звуковым давлением имеем

$$
\mathrm{E}=20 \lg \frac{\Delta \mathrm{p}}{\Delta \mathrm{p}_{\mathrm{o}}}, \text { фон }=2 \lg \frac{\Delta \mathrm{p}}{\Delta \mathrm{p}_{\mathrm{o}}}, \text { декафон. }
$$

На практике используется также шкала громкости с единицей измерения 1 сон, громкость в сонах устанавливает степенной закон Стивенса (s.s.Stevens, 1951, 1961). Этим законом утверждается, что ощущение громкости звука носит степенной характер и нарастает пропорционально интенсивности звукового стимула:

$$
\mathrm{E}_{\mathrm{coH}}=\mathrm{k} \mathrm{I} \text {. }
$$

Связь между громкостью в сонах и фонах устанавливается экспериментально (графическое соотношение показано на рис. 1, а).

Имея определенную величину в 1 сон при эталонном тоне в 1000 мел (звуке стандартной частоты 1 кГц), громкость звука в Е сонов определяется при интенсивности, в Е раз превышающей его первоначальную.

Оказывается, что оба закона: и Вебера - Фехнера, и Стивенса, - являются тождественными. В доступной литературе не обнаружено установления этого заключения, поэтому приводим собственное математическое обоснование.

\section{Результаты исследования}

для эталонного звука 1000 Гц (тона 1000 мел) между громкостью тонов в фонах и сонах установлено соотношение: $1 \mathrm{coн}=40$ фонов $=4$ дафон.

Уравнение прямой (рис. 1, а) имеет вид:

$$
\log _{2} \mathrm{E}_{\text {сон }}=\mathrm{E}_{\text {дафон }}-4=\mathrm{N}_{\mathrm{b}}-4=\lg \frac{\mathrm{I}}{\mathrm{I}_{\mathrm{O}}}-4,
$$

откуда получается закон стивенса, выраженный действительно в виде степени

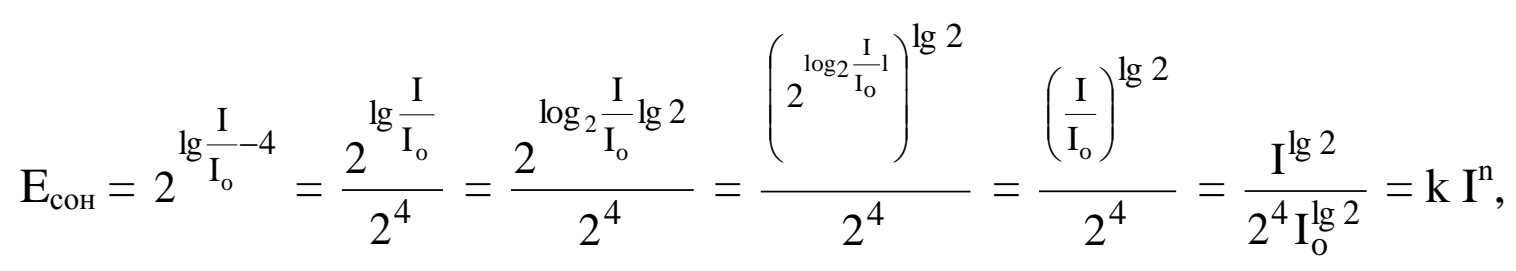


где показатель степени $\mathrm{n}=\lg 2$.

При этом коэффициент $\mathrm{k}=\frac{1}{2^{4} \mathrm{I}_{\mathrm{o}}^{\lg 2}}=256=2^{8}$ и

$\mathrm{I}_{\mathrm{o}}^{\lg 2}=2,441 \cdot 10^{-4} \frac{\mathrm{BT}}{\mathrm{M}^{2}}=2^{-12} \frac{\mathrm{BT}}{\mathrm{M}^{2}}$.

\section{Выводы}

Таким образом, утверждение, что закон Стивенса является альтернативным (А.А. Пузырей, 1976), не вполне корректно - это просто иная запись одного и того же эффекта. Однако значение закона Стивенса велико потому, что он позволяет пользоваться не относительными значениями интенсивности звука, а их абсолютными значениями (рис. 1, б).

Но, с другой стороны, закон Вебера - Фехнера устанавливает линейное определение относительной интенсивности звука, а закон Стивенса определяет эту интенсивность звука в виде степени. На рис. 2 представлены результаты собственных расчетов по установлению тождественности законов Вебера Фехнера и Стивенса. заданы константы $\mathrm{n}=\lg 2$ и Іо $=10-12$, интервал изменения возможных значений реальной интенсивности звука: $\mathrm{N} \in[-12,1]$, так что I(N) $\in$ [10-12, 10]. Приведено графическое представление величин Ефон(I) и Есон(I). Нижний график точно соответствует закону Стивенса, а верхний - показывает его степенной характер.

Более полное представлении о восприятии громкости звука слуховой системой человека показано в современных работах [17-20].
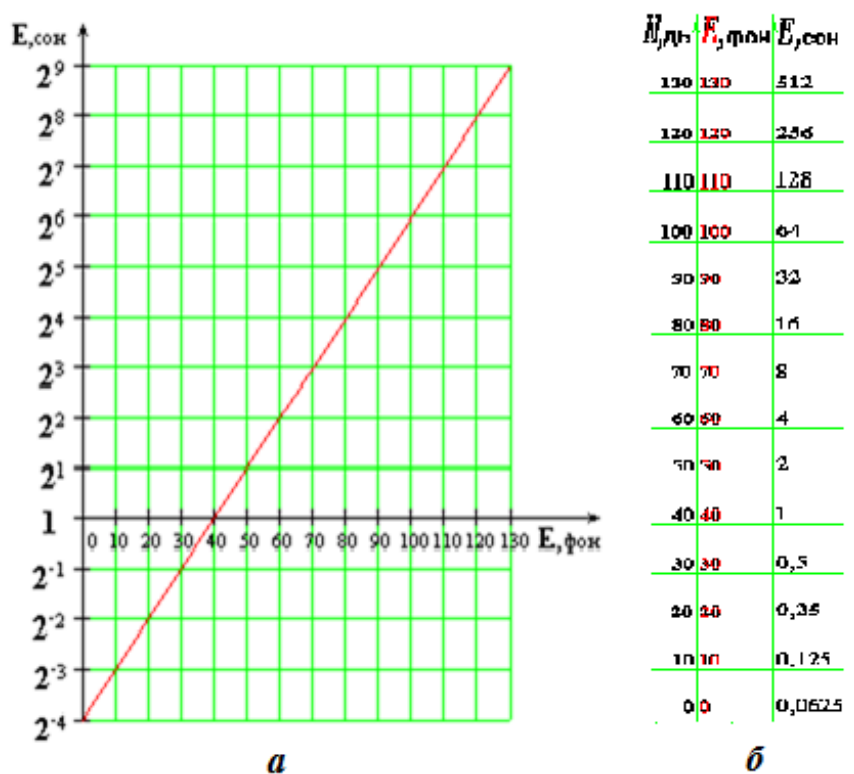

Рис. 1; а-диаграмма соответствия шкал громкости в сонах и фонах: удвоение громкости (в сонах) пропориионально увеличению стимула на 10 фонов; б - соотношения между шкалами уровней интенсивности звука (звукового давления), $N$, дБ, и уровней громкости, $E$, фон, и $E$, сон. 

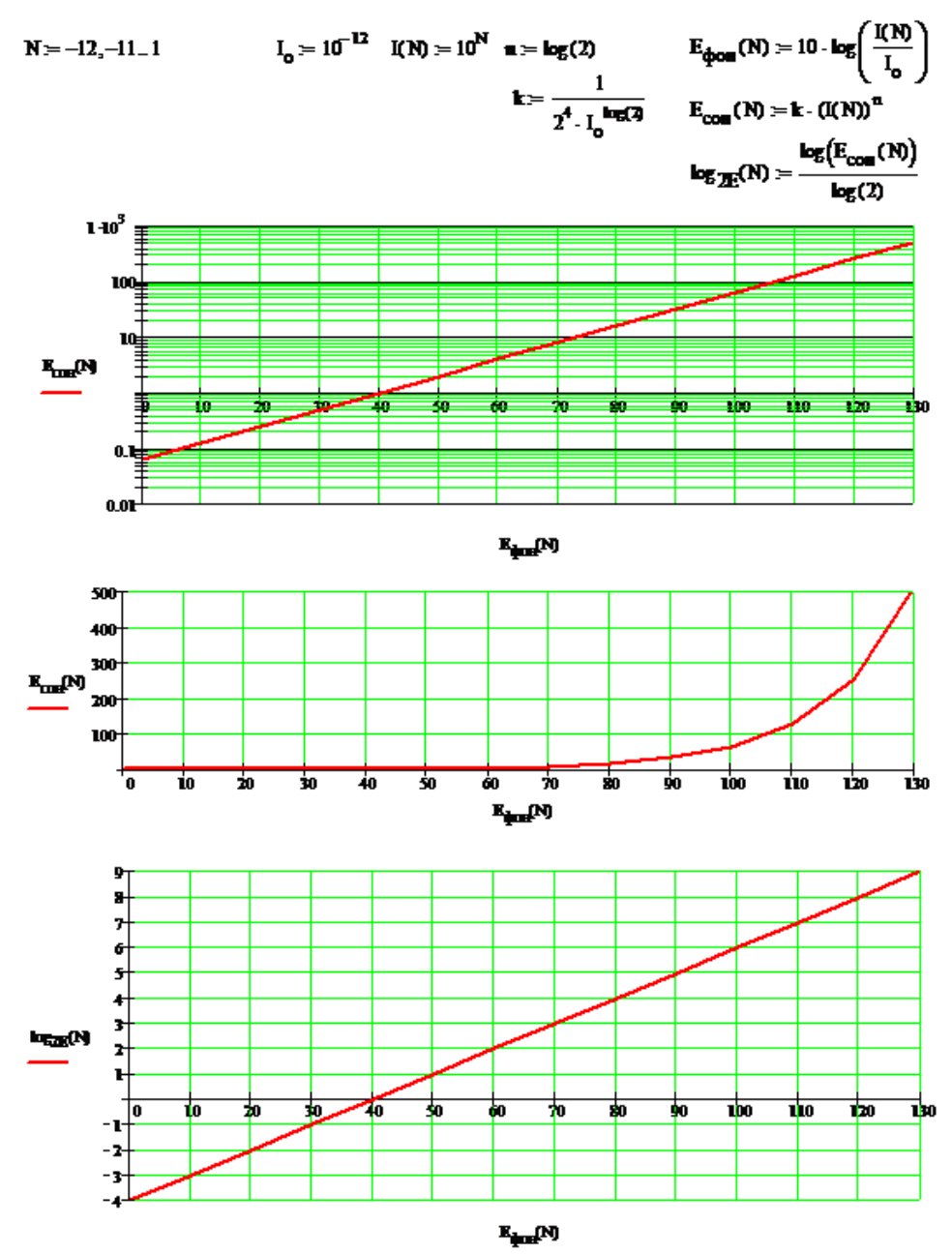

Рис.2. Результаты расчета тождественности законов Вебера - Фехнера и стивенса: верхний графикэкспериментальное (линейное) соответствие между шкалами громкости в фонах (ось абсиисс) и сонах (ось ординат), средний-степенной характер закона Стивенса, нижний-линейный (в логарифмическом представлении по основанию 2) закон Стивенса.

$* * *$

1. Helmholtz H. Die Lehre den Tonempfindungen als physiologische Grundlage für die Theorie der Musik. Braunschweig: F. Vieweg und Sohn; 1863.

2. von Békésy G. Experiments in Hearing. NY - Toronto - London: McGraw-Hill Book Co.; 1960.

3. Koenig W. A new frequency scale for acoustic measurements / W. Koenig // Bell Laboratory Record, 1949.

4. Овчинников Е.Л., Адыширин-Заде К.А., Александрова Н.А., Владимирова Т.Ю. Математическое обеспечение проблем биоакустики и психофизики слуха. 1. Дифференциальные уравнения в обосновании распределения слуховых рецепторов по частотам. // Сб.: Образование и наука: современное состояние и перспективы развития. Тамбов, 2014. С. 112-118. 
5. Овчинников Е.Л., Адыширин-Заде К.А., Александрова Н.А., Владимирова Т.Ю. Математическое обеспечение проблем биоакустики и психофизики слуха. 2. Дифференциальные уравнения в обосновании воз- растных изменений слуха. // Сб.: Образование и наука: современное состояние и перспективы развития. Тамбов, 2014. С. 118-124.

6. Овчинников Е.Л., Адыширин-Заде К.А., Александрова Н.А., Владимирова Т.Ю. Вычислительная биология внутреннего уха: апикальная связка мембран улиткового протока - от гипотезы к обсуждению. // Сб.: Наука и образование: проблемы и перспективы развития. Тамбов, 2014. С. 117-121.

7. Овчинников Е.Л., Адыширин-Заде К.А., Александрова Н.А., Владимирова Т.Ю. Вычислительная биология внутреннего уха: расчет линейных параметров улиткового протока. // Сб.: Наука и образование: проблемы и перспективы развития: Тамбов, 2014. C. 121-125.

8. Овчинников Е.Л., Ерёмина Н.В. Способ выявления биофизических процессов, реализующих механизм и биофизическую (волновую) модель слуха человека. // Патент RU № 2146878 C1 РФ от 27.03.2000 по заявке № 97111773 от 08.07.1997.

9. Овчинников Е.Л. Акустоволновая модель слуха: биофизическая концепция. Клинические приложения. // Росс. оториноларингол.- 2002. - № 3(3). - С. 71 - 76.

10. Ovchinnikov EL. Acoustic-wave hearing model, initial stage: the sound transduction in the inner ear. / E.L. Ovchinnikov, V.V. Ivanov, Yu.V. Ovchinnikova // European Science and Technology: 3nd International scientific conference, Munich, Germany, 2012, p. 524-535.

11. Ovchinnikov E.L. Acoustic-Wave Hearing Model, The Initial Stage-C: Hydroacoustics of the Inner Ear (Sound Field Formation in the Cochlea) // J. Appl. Bioinform. Comput. Biol., 2014, 3:2 , p. 1 of 6 . http://dx.doi.org/10.4172/2329-9533.1000112.

12. Овчинников Е.Л. Акустоволновая модель слуха. Монография . / Е.Л. Овчинников // Изд. ScuenceCemtre, 2016, 128 с.

13. Yashin SS, Shiryazdanov RU, Ovchinnikov EL. Bioacoustics of hearing: Part 1. Transduction in the human organ of hearing. // 53rd IEB workshop and Symposium 2016, Montpellier, France, p.n. 148-149.

14. Yashin SS, Shiryazdanov RU, Ovchinnikov EL. Bioacoustics of hearing: Part 2. Tonotopicity in the human organ of hearing. // 53rd IEB workshop and Symposium 2016, Montpellier, France, p.n. 148-149.

15. Ovchinnikov EL, Yashin SS. Metamorphosis of wave processes in inner ear: part 1. From vibrations to waves and back // 53rd IEB workshop and Symposium 2016, Montpellier, France, p.n. 159.

16. Ovchinnikov EL, Yashin SS. Metamorphosis of wave process in inner ear: part 2. Sound energy ways at pre-receptor level // 51st IEB workshop and Symposium 2014, Sheffield, UK, p.n. 160.

17. Овчинников Е.Л. Громкость звуков различных частот и интенсивностей: обобщенный закон Вебера для слуха // Наука и инновации в медицине. 2016. №1. - С.14-18.

18. Овчинников Е.Л. Акустический Декамерон: ДесятиГлав о дифференциальных уравнениях в биоакустике и психофизике слуха//Science Centre. -192 c.

19. Яшин С.С., Ширьязданов Р.У., Тарасенко Д.С., Давыдкин-Гогель М.М.. Закон Вебера Овчинникова. // Сб. Научный диалог: Вопросы медицины, по материалам международной научно-практической конференции 15 ноября 2016 г. - С. 32-40.

20. Овчинников Е.Л., Яшин С.С. Морфофункциональная основа механизмов влияния звука на слуховые рецепторы. // Сб. Научный диалог: Вопросы медицины, по материалам международной научно-практической конференции 15 июня 2017 г. - С. 30-36. 